\title{
Front Matter: Volume 8553
}

, "Front Matter: Volume 8553," Proc. SPIE 8553, Optics in Health Care and Biomedical Optics V, 855301 (7 January 2013); doi: 10.1117/12.2014549

SPIE. Event: Photonics Asia, 2012, Beijing, China 


\title{
PROGRESS IN BIOMEDICAL OPTICS AND IMAGING
}

Vol. 13, No. 42

\section{Optics in Health Care and Biomedical Optics V}

\author{
Qingming Luo \\ Ying Gu \\ Xingde D. Li \\ Editors \\ 5-7 November 2012 \\ Beijing, China \\ Sponsored by \\ SPIE \\ COS_Chinese Optical Society \\ Cooperating Organizations \\ Tsinghua University (China) • Peking University (China) • Zhejiang University (China) • Beijing \\ Institute of Technology (China) • Beijing University of Posts and Telecommunications (China) \\ University of Science and Technology of China • Tianjin University (China) • Nankai University \\ (China) • Changchun University of Science and Technology (China) • University of Shanghai for \\ Science and Technology (China) • Capital Normal University (China) • Huazhong University of \\ Science and Technology (China) - Beijing Jiaotong University (China) • Shanghai Institute of \\ Optics and Fine Mechanics (China) - Changchun Institute of Optics and Fine Mechanics (China) \\ - Institute of Semiconductors (China) - Institute of Optics and Electronics (China) - Institute of \\ Physics (China) • Shanghai Institute of Technical Physics (China) • China Instrument and Control \\ Society • Optoelectronics Technology Committee, COS (China) • SPIE National Committee in \\ China • Japan Optical Society • Korea Optical Society (Korea, Republic of) - Australia Optical \\ Society • Singapore Optical Society \\ Supporting Organizations \\ CAST_China Association for Science and Technology (China) \\ NSFC-National Nature Science Foundation (China) \\ Published by \\ SPIE
}

Volume 8553

Proceedings of SPIE, 1605-7422, v. 8553

SPIE is an international society advancing an interdisciplinary approach to the science and application of light.

Optics in Health Care and Biomedical Optics V, edited by Qingming Luo, Ying Gu, Xingde D. Li, Proc. of SPIE Vol. 8553, 855301 - (c) 2012 SPIE · CCC code: 1605-742/12/\$18

doi: $10.1117 / 12.2014549$

Proc. of SPIE Vol. $8553855301-1$ 
The papers included in this volume were part of the technical conference cited on the cover and title page. Papers were selected and subject to review by the editors and conference program committee. Some conference presentations may not be available for publication. The papers published in these proceedings reflect the work and thoughts of the authors and are published herein as submitted. The publisher is not responsible for the validity of the information or for any outcomes resulting from reliance thereon.

Please use the following format to cite material from this book:

Author(s), "Title of Paper," in Optics in Health Care and Biomedical Optics V, edited by Qingming Luo, Ying GU, Xingde D. Li, Proceedings of SPIE Vol. 8553 (SPIE, Bellingham, WA, 2012) Article CID Number.

ISSN: $1605-7422$

ISBN: 9780819493088

Published by

SPIE

P.O. Box 10, Bellingham, Washington 98227-0010 USA

Telephone +1 3606763290 (Pacific Time) · Fax +1 3606471445

SPIE.org

Copyright (C) 2012, Society of Photo-Optical Instrumentation Engineers.

Copying of material in this book for internal or personal use, or for the internal or personal use of specific clients, beyond the fair use provisions granted by the U.S. Copyright Law is authorized by SPIE subject to payment of copying fees. The Transactional Reporting Service base fee for this volume is $\$ 18.00$ per article (or portion thereof), which should be paid directly to the Copyright Clearance Center (CCC), 222 Rosewood Drive, Danvers, MA 01923. Payment may also be made electronically through CCC Online at copyright.com. Other copying for republication, resale, advertising or promotion, or any form of systematic or multiple reproduction of any material in this book is prohibited except with permission in writing from the publisher. The CCC fee code is $1605-7422 / 12 / \$ 18.00$.

Printed in the United States of America.

Publication of record for individual papers is online in the SPIE Digital Library.

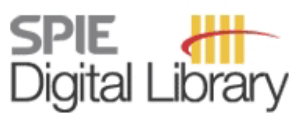

SPIEDigitalLibrary.org

Paper Numbering: Proceedings of SPIE follow an e-First publication model, with papers published first online and then in print and on CD-ROM. Papers are published as they are submitted and meet publication criteria. A unique, consistent, permanent citation identifier (CID) number is assigned to each article at the time of the first publication. Utilization of CIDs allows articles to be fully citable as soon as they are published online, and connects the same identifier to all online, print, and electronic versions of the publication. SPIE uses a six-digit CID article numbering system in which:

- The first four digits correspond to the SPIE volume number.

- The last two digits indicate publication order within the volume using a Base 36 numbering system

employing both numerals and letters. These two-number sets start with $00,01,02,03,04,05,06$, 07, 08, 09, 0A, OB ... 0Z, followed by 10-1Z, 20-2Z, etc.

The CID Number appears on each page of the manuscript. The complete citation is used on the first page, and an abbreviated version on subsequent pages. Numbers in the index correspond to the last two digits of the six-digit CID Number. 


\section{Contents}

xiii Symposium Committees

xv Conference Committee

xix Quantum dot lasers and relevant nanoheterostructures (Plenary Paper) [8552-1]

A. E. Zhukov, N. V. Kryzhanovskaya, A. V. Savelyev, A. M. Nadtochiy, E. M. Arakcheeva, F. I. Zubov, V. V. Korenev, Saint Petersburg Academic Univ. (Russian Federation); M. V. Maximov, Y. M. Shernyakov, M. M. Kulagina, I. A. Slovinskiy, loffe Physical-Technical Institute (Russian Federation); D. A. Livshits, Innolume GmbH (Germany); A. Kapsalis, C. Mesaritakis, D. Syvridis, Univ. of Athens (Greece); A. M. Mintairov, Univ. of Notre Dame (United States)

\section{SESSION 1 ADVANCED BIOMEDICAL OPTICAL TECHNIQUES}

855304 Integrated on-chip lens applied to microfluidic chips (Invited Paper) [8553-3]

Y. Zhao, Q. Li, X.-M. Hu, D.-F. Yang, Beijing Institute of Technology (China)

855305 Motion compensation of optical mapping signals from rat heart slices (Invited Paper) [8553-4]

B. Stender, Univ. zu Lübeck (Germany); M. Brandenburger, Fraunhofer Research Institution for Marine Biotechnology (Germany); B. Wang, Z. Zhang, Xi'an Jiaotong Univ. (China);

A. Schlaefer, Univ. zu Lübeck (Germany)

\section{SESSION 2 INNOVATIVE OPTICAL IMAGING METHODS I}

$8553 \mathrm{OA}$ Coherent fiber supercontinuum laser for nonlinear biomedical imaging [8553-9]

H. Tu, Y. Liu, Univ. of Illinois at Urbana-Champaign (United States); X. Liu, J. Laegsgaard, D. Turchinovich, Technical Univ. of Denmark (Denmark); S. A. Boppart, Univ. of Illinois at Urbana-Champaign (United States)

8553 OB Wide field-of-view microscopy with Talbot pattern illumination [8553-10]

J. Wu, G. Liu, Shanghai Jiao Tong Univ. (China) and Univ. of Michigan (United States)

\section{SESSION 3 PHOTONIC THERAPEUTICS}

8553 OD Indirect photobiomodulation in functional networks (Invited Paper) [8553-12]

T. C.-Y. Liu, W.-W. Zhu, X.-B. Yang, South China Normal Univ. (China) 
$8553 \mathrm{OF} \quad$ Advanced optical techniques for monitoring dosimetric parameters in photodynamic therapy (Invited Paper) [8553-15]

B. Li, Z. Qiu, Fujian Normal Univ. (China); Z. Huang, Fujian Normal Univ. (China) and Univ. of Colorado Denver (United States)

8553 OG Efficacy of gallium phthalocyanine as a photosensitizing agent in photodynamic therapy for the treatment of cancer [8553-16]

K. Maduray, B. Odhav, Durban Univ. of Technology (South Africa)

$8553 \mathrm{OH}$ Efficient photodynamic therapy against Staphylococcus aureus using [Ru(bpy)2(dppn)] ${ }^{2+}:$ a novel cationic photosensitizer [8553-17]

Y. Wang, Chinese People's Liberation Army General Hospital (China) and Nankai Univ.

(China); Y. Wang, Y. Gu, Chinese People's Liberation Army General Hospital (China)

8553 0J Polyethylene glycol-functionalized bis(arylidene)cycloalkanone photosensitizers for twophoton excited photodynamic therapy [8553-19]

Q. Zou, Technical Institute of Physics and Chemistry (China) and Graduate Univ. of the Chinese Academy of Sciences (China); H. Zhao, Chinese People's Liberation Army General Hospital (China); Y. Zhao, Technical Institute of Physics and Chemistry (China); Y. Wang, Y. Gu, Chinese People's Liberation Army General Hospital (China); F. Wu, Technical Institute of Physics and Chemistry (China)

\section{SESSION 5 INNOVATIVE OPTICAL IMAGING METHODS II}

855300 Design of an affordable fluorescence confocal laser scanning microscope for medical diagnostics [8553-24]

C. Bechtel, Technische Univ. Dresden (Germany); J. Knobbe, H. Grüger, H. Lakner, Fraunhofer-Institut für Photonische Mikrosysteme (Germany)

8553 OP Multiview hyperspectral topography of tissue structural and functional characteristics [8553-25]

S. Zhang, Univ. of Science and Technology of China (China) and The Ohio State Univ. (United States); P. Liu, Univ. of Science and Technology of China (China); J. Huang, The Ohio State Univ. (United States); R. Xu, Univ. of Science and Technology of China (China) and The Ohio State Univ. (United States)

\section{SESSION 6 OPTICAL COHERENCE TOMOGRAPHY I}

$85530 Q \quad$ Recent advances in optical coherence tomography (Invited Paper) [8553-26]

Z. Ding, C. Wang, Y. Shen, L. Huang, L. Wu, C. Du, Zhejiang Univ. (China)

8553 OS Phantom testing of a novel endoscopic OCT probe: a prelude to clinical in-vivo laryngeal use [8553-28]

T. Tatla, J. Y. Pang, Northwick Park Hospital (United Kingdom); R. Cernat, G. Dobre, Univ. of Kent (United Kingdom); P. J. Tadrous, Northwick Park Hospital (United Kingdom); A. Bradu, Univ. of Kent (United Kingdom); G. Gelikonov, V. Gelikonov, Institute of Applied Physics (Russian Federation); A. G. Podoleanu, Univ. of Kent (United Kingdom) 


\section{SESSION 7 OPTICAL COHERENCE TOMOGRAPHY II}

8553 OV In vivo integrated photoacoustic ophthalmoscopy, optical coherence tomography, and scanning laser ophthalmoscopy for retinal imaging [8553-32]

W. Song, Harbin Institute of Technology (China) and Northwestern Univ. (United States); R. Zhang, Harbin Institute of Technology (China); H. F. Zhang, Q. Wei, Northwestern Univ. (United States); W. Cao, Harbin Institute of Technology (China) and The Pennsylvania State Univ. (United States)

\section{SESSION 8 PHOTONIC DIAGNOSTICS I}

8553 OW Studying the role of macrophages in circulating prostate cancer cells by in vivo flow cytometry (Invited Paper) [8553-33]

X. Cui, J. Guo, Fudan Univ. (China); Z. Gu, Shanghai Jiao Tong Univ. (China); X. Wei, Fudan Univ. (China) and Shanghai Jiao Tong Univ. (China)

$8553 \mathrm{OZ}$ Simulating the demyelination of a nerve fiber by action potential encoded second harmonic generation [8553-36]

H. Yang, Z. Luo, X. Chen, Y. Huang, S. Xie, Fujian Normal Univ. (China)

\section{SESSION 9 PHOTONIC DIAGNOSTICS II}

855311 Identification of non-neoplastic and neoplastic gastric polyps using multiphoton microscopy (Invited Paper) [8553-38]

S. Jiang, Fujian Normal Univ. (China); D. Kang, M. Xu, Fujian Medical Univ. (China); X. Zhu,

S. Zhuo, J. Chen, Fujian Normal Univ. (China)

855312 Collagen fiber spatial orientation mapping using polarization-sensitive SHG microscopy [8553-39]

V. A. Hovhannisyan, P.-S. Hu, C.-Y. Dong, National Taiwan Univ. (Taiwan)

855313 Measuring intracellular calcium dynamics of HeLa cells exposed to nitric oxide by microplate fluorescence reader [8553-40]

Y. Huang, J. Chen, H. Yang, L. Zheng, Y. Wang, H. Li, S. Xie, Fujian Normal Univ. (China)

855314 Metabolic changes of cultured DRG neurons induced by adenosine using confocal microscopy imaging [8553-41]

L. Zheng, Y. Huang, J. Chen, Y. Wang, H. Yang, Y. Zhang, S. Xie, Fujian Normal Univ. (China)

\section{SESSION 10 PHOTONIC DIAGNOSTICS III}

855318 Nonlinear optical imaging characteristics of colonic adenocarcinoma using multiphoton microscopy [8553-45]

N. Liu, R. Chen, H. Li, J. Chen, Fujian Normal Univ. (China) 
855319 Molecular application of spectral photoacoustic imaging in pancreatic cancer pathology [8553-46]

M. Lakshman, C. Hupple, VisualSonics Inc. (Canada); I. Lohse, Ontario Cancer Institute (Canada) and Campbell Family Cancer Research Institute (Canada); D. Hedley, Ontario Cancer Institute (Canada), Campbell Family Cancer Research Institute (Canada), and Univ. of Toronto (Canada); A. Needles, C. Theodoropoulos, VisualSonics Inc. (Canada)

\section{SESSION 11 INNOVATIVE MICROSCOPY IMAGING METHOD}

85531 A Dynamics of two-photon two-color transitions in flurophores excited by femtosecond laser pulses (Invited Paper) [8553-47]

P. S. Shternin, A. G. Smolin, O. S. Vasyutinskii, loffe Insitute (Russian Federation); S. Denicke, S. Herbrich, K.-H. Gericke, Technische Univ. Braunschweig (Germany)

8553 1B CW STED nanoscopy with a Ti:Sapphire oscillator [8553-49]

Y. Liu, Shanghai Jiao Tong Univ. (China) and Peking Univ. (China); H. Xie, Peking Univ. (China); E. Alonas, P. J. Santangelo, Georgia Institute of Technology and Emory Univ. School of Medicine (United States); D. Jin, Macquarie Univ. (Australia); P. Xi, Peking Univ. (United States)

8553 IC LOSOM: phase relief imaging can be achieved with confocal system [8553-50] T. Peng, Peking Univ. (China) and Xi'an Univ. of Technology (China); H. Xie, Y. Ding, Peking Univ. (China); Y. Lu, D. Jin, Macquarie Univ. (Australia); P. Xi, Peking Univ. (China)

8553 1D Design of a real-time portable confocal scanning laser microscope [8553-52]

$X$. Yang, Peking Univ. (China) and Xi'an Univ. of Technology (China); Y. Zhao, Peking Univ. (China); G. Yin, Shanghai Bandweave Technologies Co. Ltd. (China); H. Li, Peking Univ. (China) and Xi'an Univ. of Technology (China); T. Wang, P. Xi, Peking Univ. (China)

\section{SESSION 12 MUTIMODE IMAGING}

$85531 \mathrm{E}$ Photo-acoustic excitation and detection of guided ultrasonic waves in bone samples covered by a soft coating layer [8553-53]

Z. Zhao, Univ. of Oulu (Finland); P. Moilanen, Univ. of Jyväskylä (Finland); P. Karppinen, Univ. of Helsinki (Finland); M. Määttä, Univ. of Oulu (Finland); T. Karppinen, E. Haeggström, Univ. of Helsinki (Finland); J. Timonen, Univ. of Jyväskylä (Finland); R. Myllylä, Univ. of Oulu (Finland)

$8553 \mathrm{IF} \quad$ ICG-loaded microbubbles for multimodal billiary imaging in cholecystectomy [8553-54] R. Qin, S. Melvin, The Ohio State Univ. (United States); R. X. XU, The Ohio State Univ. (United States) and Univ. of Science and Technology of China (China)

8553 IG Multimodal imaging of ischemic wounds [8553-55]

S. Zhang, Univ. of Science and Technology of China (China) and The Ohio State University (United States); S. Gnyawali, J. Huang, The Ohio State Univ. (United States); P. Liu, Univ. of Science and Technology of China (China); G. Gordillo, C. K. Sen, The Ohio State Univ. (United States); R. XU, Univ. of Science and Technology of China (China) and The Ohio State Univ. (United States) 
$8553 \mathrm{lH} \quad$ Novel coaxial atomization processes for microfabrication of multi-layered biodegradable microcapsules [8553-56]

T. Si, Univ. of Science and Technology of China (China); L. Zhang, The Ohio State Univ. (United States); G. Li, Univ. of Science and Technology of China (China); R. XU, Univ. of Science and Technology of China (China) and The Ohio State Univ. (United States)

\section{SESSION 13 OPTICS IMAGING ALGORITHMS AND ANALYSIS I}

$855311 \quad$ Electromagnetic scattering from biological tissue [8553-57]

Z. Tong, O. Korotkova, Univ. of Miami (United States)

$85531 \mathrm{~J} 3 \mathrm{D}$ reconstruction for endoscopic environment based on optical tracker [8553-58]

B. Yang, Y. Zhou, X. Hu, J. Lin, Q. Xing, Beijing Institute of Technology (China)

8553 IL Photoacoustic imaging: a potential new tool for arthritis (Invited Paper) [8553-128]

$X$. Wang, Univ. of Michigan Health System (United States)

SESSION 14 OPTICS IMAGING ALGORITHMS AND ANALYSIS II

855310 Investigating the backscattering characteristics of individual normal and cancerous cells based on experimentally determined three-dimensional refractive index distributions [8553-64]

W.-C. Hsu, J.-W. Su, C.-C. Chang, K.-B. Sung, National Taiwan Univ. (Taiwan)

8553 IP Cost-effective approaches for high-resolution bioimaging by time-stretched confocal microscopy at $1 \mu \mathrm{m}$ [8553-65]

T. T. W. Wong, Y. Qiu, A. K. S. Lau, J. Xu, A. C. S. Chan, K. K. Y. Wong, K. K. Tsia, The Univ. of Hong Kong (Hong Kong, China)

8553 1Q Quantitative interferometric microscopy: tool for phase imaging from 2D to 3D [8553-66]

S. Wang, L. Xue, J. Lai, Y. Song, Z. Li, Nanjing Univ. of Science and Technology (China)

\section{SESSION 15 SPECTROSCOPY FOR BIOMEDICAL APPLICATION}

8553 IR Fast reconstruction of Raman spectra from narrow-band measurements based on Wiener estimation [8553-67]

S. Chen, Y. H. Ong, Q. Liu, Nanyang Technological Univ. (Singapore)

8553 is Evaluation of human dentine demineralization of yellow race by Raman spectra [8553-68] Z. Zhan, W. Guo, H. Liu, X. Zhang, S. Xie, Fujian Normal Univ. (China)

8553 iT Assessment of skin flap viability using visible diffuse reflectance spectroscopy and autofluorescence spectroscopy [8553-69]

C. Zhu, S. Chen, Nanyang Technological Univ. (Singapore); C. H.-K. Chui, Singapore General Hospital (Singapore); Q. Liu, Nanyang Technological Univ. (Singapore) 
$85531 \mathrm{U}$ Characterization and differentiation of normal and abnormal semen samples using microRaman spectroscopy [8553-70]

Z. Huang, X. Chen, Fujian Normal Univ. (China); J. Chen, Fujian Provincial Hospital (China);

Y. Li, J. Lei, R. Chen, Fujian Normal Univ. (China)

$85531 \mathrm{~V}$ Brain cancer probed by native fluorescence and stokes shift spectroscopy [8553-71]

Y. Zhou, Chinese People's Liberation Army General Hospital (China); C. Liu, The City

College of New York, CUNY (United States); Y. He, Beijing Normal Univ. (China); Y. Pu, The

City College of New York, CUNY (United States); Q. Li, W. Wang, BeiHang Univ. (China);

R. R. Alfano, The City College of New York, CUNY (United States)

\section{SESSION 16 LASER-TISSUE INTERACTION}

8553 IX Rabbit electroretinograms evoked by $632.8 \mathrm{~nm}$ laser flash stimuli [8553-74]

Z.-F. Yang, Beijing Institute of Radiation Medicine (China); H.-X. Chen, People's Liberation Army General Hospital (China); J.-R. Wang, B.-L. Guan, Beijing Institute of Radiation Medicine (China); G.-Y. Yu, People's Liberation Army General Hospital (China); X.-N. Zhang, W.-Y. Zhang, J.-G. Yang, Beijing Institute of Radiation Medicine (China)

$85531 \mathrm{Y}$ The threshold of vapor channel formation in water induced by pulsed $\mathrm{CO}_{2}$ laser [8553-75] W. Guo, X. Zhang, Z. Zhan, S. Xie, Fujian Normal Univ. (China)

855312 Mechanisms of interaction between very high-frequency photoacoustic waves and the skin [8553-76]

G. F. F. Sá, C. Serpa, L. G. Arnaut, Univ. de Coimbra (Portugal)

\section{POSTER SESSION}

855320 A method of simulating polarization-sensitive optical coherence tomography based on a polarization-sensitive Monte Carlo program and a sphere cylinder birefringence model [8553-63]

D. Chen, N. Zeng, C. Liu, Key Lab. for Minimal Invasive Medical Technologies (China); H. Ma, Key Lab. for Minimal Invasive Medical Technologies (China) and Tsinghua Univ. (China)

855321 Temperature changes in the pulp chamber during dentin ablation with Er:YAG laser [8553-73]

X. Zhang, H. Zhao, Z. Zhan, W. Guo, S. Xie, Fujian Normal Univ. (China)

855322 Second harmonic generation imaging of skin wound healing and scarring in a rabbit ear model [8553-79]

Y. Tang, Fujian Normal Univ. (China) and Fujian Medical Univ. (China); X. Zhu, Fujian Normal Univ. (China); S. Xiong, Fujian Medical Univ. (China); J. Chen, Fujian Normal Univ. (China)

855323 Study of $A B O$ blood types by combining membrane electrophoresis with surfaceenhanced Raman spectroscopy [8553-80]

J. Wang, J. Lin, Z. Huang, Fujian Normal Univ. (China); L. Sun, First Hospital of Fuzhou (China); Y. Shao, Shenzhen Univ. (China); P. Lu, W. Shi, J. Lin, R. Chen, Fujian Normal Univ. (China) 
855325 Surface-enhanced Raman spectroscopy study of radix astragali based on soxhlet extractor [8553-82]

P. Lu, J. Lin, N. Liu, Fujian Normal Univ. (China); Y. Shao, Shenzhen Univ. (China); J. Wang,

W. Shi, J. Lin, R. Chen, Fujian Normal Univ. (China)

855326 Photo-induced electron transfer between dendritic zinc(II) phthalocyanine bearing carboxylic terminal groups and methyl viologen [8553-83]

Y. Wang, J. Chen, L. Huang, S. Xie, H. Yang, Y. Peng, Fujian Normal Univ. (China)

855327 Cutaneous pain effects induced by Nd:YAG and $\mathrm{CO}_{2}$ laser stimuli [8553-84]

J.-R. Wang, Beijing Institute of Radiation Medicine (China); G.-Y. Yu, People's Liberation Army General Hospital (China); Z.-F. Yang, Beijing Institute of Radiation Medicine (China); H.-X. Chen, People's Liberation Army General Hospital (China); D.-D. Hu, Beijing Institute of Radiation Medicine (China); X.-B. Zou, People's Liberation Army General Hospital (China)

855328 Distinction of gastric cancer tissue based on surface-enhanced Raman spectroscopy [8553-85]

J. Ma, H. Zhou, L. Gong, S. Liu, Z. Zhou, Ocean Univ. of China (China); W. Mao, Qingdao Municipal Hospital (China); R. Zheng, Ocean Univ. of China (China)

855329 Error analysis of image acquisition by moving objective lens [8553-86]

H. Xie, H. Chen, Y. Cai, F. Yang, Guangxi Univ. (China)

8553 2A Reverse propagation properties of light wave in tapered micro-nano fiber for cell endoscopy [8553-87]

D. Zhou, J. Zhong, Jinan Univ. (China)

8553 2C Polyion complex micelles incorporating poly (aryl benzyl ether) dendritic phthalocyanine: effective photosensitizers for enhanced photodynamic therapy [8553-89]

K. Chen, M. Yu, H. Zhang, D. Ma, S. Pang, W. Huang, Y. Peng, Fujian Normal Univ. (China)

8553 2D Ultra-long scan depth optical coherence tomography for imaging the anterior segment of human eye [8553-90]

D. Zhu, M. Shen, L. Leng, Wenzhou Medical College (China)

8553 2G Quadratic trianqular element for diffuse optical tomography [8553-93]

X. Zhang, Y. Deng, J. Xu, Z. Luo, H. Gong, Q. Luo, Huazhong Univ. of Science and Technology (China)

8553 2J Photoacoustic measurement for glucose solution concentration based on tunable pulsed laser induced ultrasound [8553-96]

Z. Ren, G. Liu, Z. Huang, D. Zhao, Jiangxi Science and Technology Normal Univ. (China)

$85532 \mathrm{~L} \quad$ Expansion of scattered phase matrix based on Zernike polynomials [8553-98]

H. Ye, Z. Gao, Q. Wang, K. Bao, X. Yang, Nanjing Univ. of Science and Technology (China)

$85532 \mathrm{M}$ Optical-resolution photoacoustic microscopy for imaging blood vessels in vivo [8553-99]

Y. Yuan, South China Normal Univ. (China)

$85532 \mathrm{~N} \quad$ Optical characters of prostate using nonlinear optical microscopy [8553-100]

S. Wu, H. Li, X. Zhang, Y. Wang, D. Peng, Fujian Normal Univ. (China) 
$85532 \mathrm{P} \quad$ Effect of apertures in ultrasound-modulated optical tomography with photomultiplier tube [8553-102]

L. Zhu, S. Ran, Z. Lin, H. Li, Fujian Normal Univ. (China)

$85532 Q \quad$ The tapered-tip single fiber optical tweezers and its multi-trapping [8553-103]

X. Guo, Z. Liu, Y. Zhao, L. Yuan, Harbin Engineering Univ. (China)

$85532 R \quad$ Scattering properties of normal and cancerous tissues from human stomach based on phase-contrast microscope [8553-104]

H. Zhang, Z. Li, H. Li, Fujian Normal Univ. (China)

855325 Retrieval of atmospheric visibility from multi-axis differential optical absorption spectroscopy [8553-105]

H. J. Zhou, Univ. of Science and Technology of China (China) and Anhui Institute of Optics and Fine Mechanics (China); W. Q. Liu, F. Q. Si, Anhui Institute of Optics and Fine Mechanics (China)

8553 2T Monte Carlo simulation of photon coherent behavior in half linfinite turbid medium by scaling method [8553-106]

L. Lin, Guangdong Medical College (China); M. Zhang, H. Liu, Dongguan Univ. of Technology (China)

$85532 \mathrm{U}$ In vivo detection of hemoglobin oxygen saturation and carboxyhemoglobin saturation variations with photoacoustic microscopy [8553-107]

Z. Chen, S. Yang, D. Xing, South China Normal Univ. (China)

$85532 \mathrm{~V} \quad$ Photoacoustic imaging of prostate cancer using cylinder diffuse radiation [8553-108] W. Xie, L. Li, Z. Li, H. Li, Fujian Normal Univ. (China)

$85532 \mathrm{~W}$ Realization of the ergonomics design and automatic control of the fundus cameras [8553-109]

C. Zeng, Z. Xiao, S. Deng, X. Yu, Guilin Univ. of Electronic Technology (China)

$85532 Y \quad$ Study the effect of temperature on optical properties of biological tissue-simulating phantom based on OCT [8553-11 1 ]

Y. He, H. Li, Fujian Normal Univ. (China)

$85532 Z$ Miniature interferometer for refractive index measurement in microfluidic chip [8553-112] M. Chen, Univ. of Shanghai for Science and Technology (China); M. Geiser, F. Truffer, Univ. of Applied Sciences Western Switzerland (Switzerland); C. Song, Univ. of Shanghai for Science and Technology (China)

855330 Study for noninvasive determination of optical properties of bio-tissue using spatially resolved diffuse reflectance [8553-113]

D. Peng, Fujian Normal Univ. (China) and Jimei Univ. (China); H. Li, Fujian Normal Univ. (China)

855331 Development of an in situ magnetic beads based RT-PCR method for electrochemiluminescent detection of rotavirus [8553-114]

F. Zhan, X. Zhou, South China Normal Univ. (China) 
855332 ERK-dependent activation of $\mathrm{Sp} 1$ is required for low-power laser irradiation-induced vascular endothelial cell proliferation [8553-115]

J. Feng, D. Xing, South China Normal Univ. (China)

855333 Iterative reconstruction for bioluminescence tomography with total variation regularization [8553-117]

W. Jin, Peking Univ. (China); Y. He, Beijing Aerospace Control Ctr. (China)

855334 Imaging the morphological change of tissue structure during the early phase of esophageal tumor progression using multiphoton microscopy [8553-118]

J. Xu, Fujian Normal Univ. (China); D. Kang, M. Xu, Fujian Medical Univ. (China); X. Zhu,

S. Zhuo, J. Chen, Fujian Normal Univ. (China)

855336 Amplification-free detection of miRNA via an ECL chips system [8553-120]

W. Liu, X. Zhou, South China Normal Univ. (China)

855337 Label-free and sensitive fluorescence detection of nucleic acid, based on combination of a graphene oxid /SYBR green I dye platform and polymerase assisted signal amplification [8553-121]

X. Zhu, D. Xing, South China Normal Univ. (China)

855339 Photoacoustic spectroscopic differences between normal and malignant thyroid tissues [8553-123]

L. Li, W. Xie, H. Li, Fujian Normal Univ. (China)

8553 3A Ex-vivo endoscopic laryngeal cancer imaging using two forward-looking fiber optic scanning endoscope probes [8553-124]

R. Cernat, Univ. of Kent (United Kingdom); T. Tatla, J.-Y. Pang, P. J. Tadrous, Northwick Park Hospital (United Kingdom); G. Gelikonov, V. Gelikonov, Institute of Applied Physics (Russian Federation); Y.-Y. Zhang, Johns Hopkins Univ. (United States); A. Bradu, Univ. of Kent (United Kingdom); X. D. Li, Johns Hopkins Univ. (United States); A. G. Podoleanu, Univ. of Kent (United Kingdom)

8553 3B Glucose and temperature sensitive luminescence ZnCdS nanoparticles [8553-125] V. I. Kochubey, E. K. Volkova, J. G. Konyukhova, N.G. Chernyshevsky Saratov State Univ. (Russian Federation)

$85533 \mathrm{C}$ Characterization of muscle stretching and damage using polarization-sensitive optical coherence tomography (PS-OCT) [8553-126]

D. Chen, N. Zeng, C. Liu, H. Ma, Tsinghua Univ. (China)

Author Index 
Proc. of SPIE Vol. $8553855301-12$

Downloaded From: https://www.spiedigitallibrary.org/conference-proceedings-of-spie on 26 Apr 2023 Terms of Use: https://www.spiedigitallibrary.org/terms-of-use 


\title{
Symposium Committees
}

\author{
General Chairs
}

Eustace L. Dereniak, College of Optical Sciences, The University of Arizona (United States)

Bingkun Zhou, Tsinghua University (China)

General Cochairs

Arthur Chiou, National Yang-Ming University (Taiwan, China)

Zhizhan Xu, Shanghai Institute of Optics and Fine Mechanics (China) Jianlin Cao, China Ministry of Science and Technology (China) Junhao Chu, Shanghai Institute of Technical Physics (China)

Technical Program Chairs

Songlin Zhuang, Shanghai University of Science and Technology (China)

Xingde Li, Johns Hopkins University (United States)

Technical Program Cochairs

Qiming Wang, Institute of Semiconductors (China)

Xu Liu, Zhejiang University (China)

Daoyin Yu, Tianjin University (China)

Qihuang Gong, Peking University (China)

Tianchu Li, National Institute of Metrology (China)

Wei Huang, Nanjing University of Posts and Telecommunications (China)

Local Organizing Committee Chair

Guangcan Guo, University of Science and Technology of China (China) 
Local Organizing Committee Cochairs

Guoqiang Ni, Beijing Institute of Technology (China)

Shusen Xie, Fujian Normal University (China)

Xiaomin Ren, Beijing University of Posts and Telecommunications (China)

Ying Gu, People's Liberation Army General Hospital (China)

Huilin Jiang, Changchun University of Science and Technology (China)

General Secretary

Qihuang Gong, Peking University (China)

Local Organizing Committee

Yan Li, Chinese Optical Society/Peking University (China)

Zhiping Zhou, Peking University (China)

Changhe Zhou, Shanghai Institute of Optics and Fine Mechanics (China)

Qingming Luo, Huazhong University of Science and Technology (China)

Chongxiu Yu, Beijing University of Posts and Telecommunications (China)

Hongda Chen, Institute of Semiconductors (China)

Yongtian Wang, Beijing Institute of Technology (China)

Yiping Cui, Southeast University (China)

Xuping Zhang, Nanjing University (China)

Feijun Song, Daheng Corporation (China)

Cunlin Zhang, Capital Normal University (China)

Yanting Lu, Nanjing University (China)

Yuejin Zhao, Beijing Institute of Technology (China)

Chunqing Gao, Beijing Institute of Technology (China)

Tiegen Liu, Tianjin University (China)

Xiaocong Yuan, Nankai University (China)

Weimin Chen, Chongqing University (China)

Zhongwei Fan, Academy of Optoelectronics (China)

Hanyi Zhang, Tsinghua University (China)

Lan Wu, Zhejiang University (China)

Yongsheng Zhang, University of Science and Technology of China (China)

Hong Yang, Peking University (China)

Xiaoying Li, Tianjin University (China)

Lin Zhai, Chinese Optical Society (China) 


\title{
Conference Committee
}

\author{
Conference Chairs
}

Qingming Luo, Huazhong University of Science and Technology (China)

Ying Gu, Chinese People's Liberation Army General Hospital (China)

Xingde D. Li, Johns Hopkins University (United States)

\section{Conference Program Committee}

Jing Bai, Tsinghua University (China)

Stephen A. Boppart, University of Illinois at Urbana-Champaign (United States)

Wei R. Chen, University of Central Oklahoma (United States)

Yu Chen, University of Maryland, College Park (United States)

Linhong Deng, Chongqing University (China)

Zhihua Ding, Zhejiang University (China)

Qiyong Gong, West China Hospital of Sichuan University, West China School of Medicine (China)

Hui Li, Fujian Normal University (China)

Hong Liu, The University of Oklahoma (United States)

Hui Ma, Tsinghua University (China)

Atsushi Maki, Hitachi, Ltd. (Japan)

Yingtian Pan, Stony Brook University (United States)

Paras N. Prasad, University at Buffalo (United States)

Yuwen Qin, National Natural Science Foundation (United States)

Qiushi Ren, Peking University (China)

Jie Tian, Institute of Automation (China)

Valery V. Tuchin, N.G. Chernyshevsky Saratov State University (Russian Federation)

Lihong V. Wang, Washington University in St. Louis (United States)

Ruikang K. Wang, University of Washington (United States)

Xun-Bin Wei, Shanghai Jiao Tong University (China)

Xujie Xia, Affiliated First People's Hospital, Shanghai Jiao Tong University (China)

Da Xing, South China Normal University (China)

Kexin Xu, Tianjin University (China)

Yudong Zhang, Institute of Optics and Electronics (China)

Zhenxi Zhang, Xi'an Jiaotong University (China)

Dan Zhu, Huazhong University of Science and Technology (China) 


\section{Session Chairs}

1 Advanced Biomedical Optical Techniques

Xingde Li, Johns Hopkins University (United States)

2 Innovative Optical Imaging Methods I

Valery V. Tuchin, N.G. Chernyshevsky Saratov State University (Russian Federation)

3 Photonic Therapeutics

Ying Gu, Chinese People's Liberation Army General Hospital (China)

4 Photodynamic Therapy

Wei R. Chen, University of Central Oklahoma (United States)

5 Innovative Optical Imaging Methods II

Ronald Xu, The Ohio State University (United States)

6 Optical Coherence Tomography I

Valery V. Tuchin, N.G. Chernyshevsky Saratov State University (Russian Federation)

7 Optical Coherence Tomography II

Xingde D. Li, Johns Hopkins University (United States)

8 Photonic Diagnostics I

Xun-Bin Wei, Shanghai Jiao Tong University (China)

9 Photonic Diagnostics II

Xun-Bin Wei, Shanghai Jiao Tong University (China)

10 Photonic Diagnostics III

Buhong Li, Fujian Normal University (China)

11 Innovative Microscopy Imaging Method

Zhihua Ding, Zhejiang University (China)

12 Mutimode Imaging

Qin Li, Beijing Institute of Technology (China)

13 Optics Imaging Algorithms and Analysis I

Xincheng Yao, The University of Alabama at Birmingham (United States)

14 Optics Imaging Algorithms and Analysis II Zhihua Ding, Zhejiang University (China) 
15 Spectroscopy for Biomedical Application

Dan Zhu, Huazhong University of Science and Technology (China)

16 Laser-Tissue Interaction

Tianhong Dai, Massachusetts General Hospital (United States)

Proc. of SPIE Vol. $8553855301-17$

Downloaded From: https://www.spiedigitallibrary.org/conference-proceedings-of-spie on 26 Apr 2023 Terms of Use: https://www.spiedigitallibrary.org/terms-of-use 
Proc. of SPIE Vol. $8553855301-18$

Downloaded From: https://www.spiedigitallibrary.org/conference-proceedings-of-spie on 26 Apr 2023 Terms of Use: https://www.spiedigitallibrary.org/terms-of-use 


\title{
Quantum dot lasers and relevant nanoheterostructures
}

\author{
Alexey E. Zhukov*a, Natalia V. Kryzhanovskaya a , Artem V. Savelyeva, Alexey M. Nadtochiy, \\ Ekaterina M. Arakcheeva ${ }^{\mathrm{a}}$, Fedor I. Zubov ${ }^{\mathrm{a}}$, Vladimir V. Korenev ${ }^{\mathrm{a}}$, Mikhail V. Maximov ${ }^{\mathrm{b}}$, Yuri M. \\ Shernyakov $^{\mathrm{b}}$, Marina M. Kulagina ${ }^{\mathrm{b}}$, Ilia A. Slovinskiy ${ }^{\mathrm{b}}$, Daniil A. Livshits ${ }^{\mathrm{c}}$, Alexandros Kapsalis ${ }^{\mathrm{d}}$, \\ Charis Mesaritakis ${ }^{\mathrm{d}}$, Dimitris Syvridis ${ }^{\mathrm{d}}$, Alexander Mintairov ${ }^{\mathrm{e}}$ \\ ${ }^{a}$ St. Petersburg Academic University, Khlopina 8(3), St Petersburg, Russia 194021; ' $\mathrm{I}$ Ioffe Physical- \\ Techical Institute, Politekhnicheskaya 26, St Petersburg, Russia 194021; ' Innolume GmbH, Konrad-

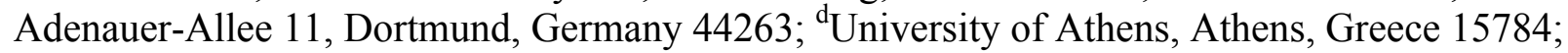 \\ ${ }^{\mathrm{e} U n i v e r s i t y ~ o f ~ N o t r e ~ D a m e, ~} 275$ Fitzpatrick Hall, Notre Dame, IN 46556, USA
}

\begin{abstract}
Spectral and power characteristics of QD stripe lasers operating in two-state lasing regime have been studied in a wide range of operation conditions. It was demonstrated that neither self-heating nor increase of the homogeneous broadening are responsible for quenching of the ground-state lasing beyond the two-state lasing threshold. It was found that difference in electron and hole capture rates strongly affects light-current curve. Modulation $p$-type doping is shown to enhance the peak power of GS lasing transition. Microring and microdisk structures $(D=4-9 \mu \mathrm{m})$ comprising $1.3 \mu \mathrm{m}$ InAs/InGaAs quantum dots have been fabricated and studied by $\mu$-PL and NSOM. Ground-state lasing was achieved well above root temperature (up to $380 \mathrm{~K}$ ). Effect of inner diameter on threshold characteristics was evaluated.
\end{abstract}

Keywords: Quantum dots, semiconductor laser, microring resonator, two-state lasing

\section{INTRODUCTION}

For various applications, including optical data transmission, pumping of Raman amplifiers, aesthetic laser surgery, etc, efficient lasers operating around $1.3 \mu \mathrm{m}$ are requested. Lasers based on self-organized InAs/InGaAs quantum dots (QDs) offer an attractive combination of the required wavelength with extremely low threshold current density and high characteristic temperature. However, at sufficiently high currents a shorter-wavelength $(\lambda \sim 1.2 \mu \mathrm{m})$ band caused by the first excited-state (ES1) transition appears in the spectrum ${ }^{1}$. Such a behavior is now referred to as two-state lasing. For a majority of applications two-state lasing has to be suppressed whereas the GS spectral component of the lasing spectrum has to be maximized. Analysis of QD laser behavior based on rate $^{2}$ and master ${ }^{3}$ equations predicts that optical power of the GS component reaches its maximal value at threshold of the two-state lasing and then persists. However a number of experimental facts revealed that the GS component declines down to its complete quenching ${ }^{4,5}$ due probably to laser selfheating in $\mathrm{CW}$ regime ${ }^{4}$ and/or increase of homogeneous broadening ${ }^{5}$ have been proposed. To clarify possible reasons of the GS lasing quenching we studied spectral and light-current characteristics of broad-area QD lasers.

Microdisks and microrings optical resonators comprising a III-V active region are promising candidates for light emitters to be integrated with silicon photonic circuits. Owing to a combination of a compact size and a high Q-factor, which can be achieved in such structures, ultralow threshold operation is expected. Although the majority of whispering gallery mode (WGM) resonators has been contained quantum-well active region composed of InP-based materials ${ }^{6}$, QDs may have certain advantages. These include attainability of $1.3 \mu \mathrm{m}$ emission in GaAs-based structures with high refractive index contrast, low temperature sensitivity, suppressed sidewall recombination rates ${ }^{7}$, making it possible to achieve lasing in resonators of small diameter. Since the first report ${ }^{8}$ on QD microdisk laser capable of operating at $77 \mathrm{~K}$, significant progress has been made toward high-temperature lasing. In particular, room-temperature lasing has been reported to date for microdisks of few microns in diameter ${ }^{9}$, whereas for relatively large microrings $(35-85 \mu \mathrm{m})$ lasing has been recently extended up to $50^{\circ} \mathrm{C}^{10}$. In the present work we demonstrate ground-state lasing up to $107^{\circ} \mathrm{C}$ for optically pumped microring lasers (MRLs) having an outer diameter as small as 6-7 $\mu \mathrm{m}$.

*zhukale@gmail.com; phone 7812 4488594; fax 7812 4486994; www.spbau.ru

Semiconductor Lasers and Applications V, edited by Ning Hua Zhu, Jinmin Li, Frank H. Peters, Changyuan Yu, Proc. of SPIE Vol. 8552, 855202 - (c) 2012 SPIE · CCC code: 0277-786/12/\$18 · doi: 10.1117/12.2009055 


\section{TWO-STATE LASING AND ITS SUPPRESSION IN QD LASERS}

\subsection{Quenching of GS spectral component}

Epitaxial structures comprising a single plane or multiple planes of InAs/InGaAs QDs were grown by molecular beam epitaxy. Stripe lasers of various cavity lengths were tested in pulse regime (300ns @ $2 \mathrm{kHz}$ ) on temperature-stabilized heatsink. An evolution of the lasing spectrum with increasing the pump current is shown in Figure 1,a for a 4-mm-long single-QD-plane laser at $17^{\circ} \mathrm{C}$. The corresponding light-current characteristics (total output power and optical power of GS and ES1 spectral components of the spectrum) are presented in Figure 1,b. The ES1 band (around $1.18 \mu \mathrm{m}$ ) appears in the spectrum at approximately $3 \mathrm{~A}$ whereas the GS component reaches its maximum at $5 \mathrm{~A}$, well beyond the onset of two-state lasing. A complete quenching of the GS lasing is observed at $12 \mathrm{~A}$.
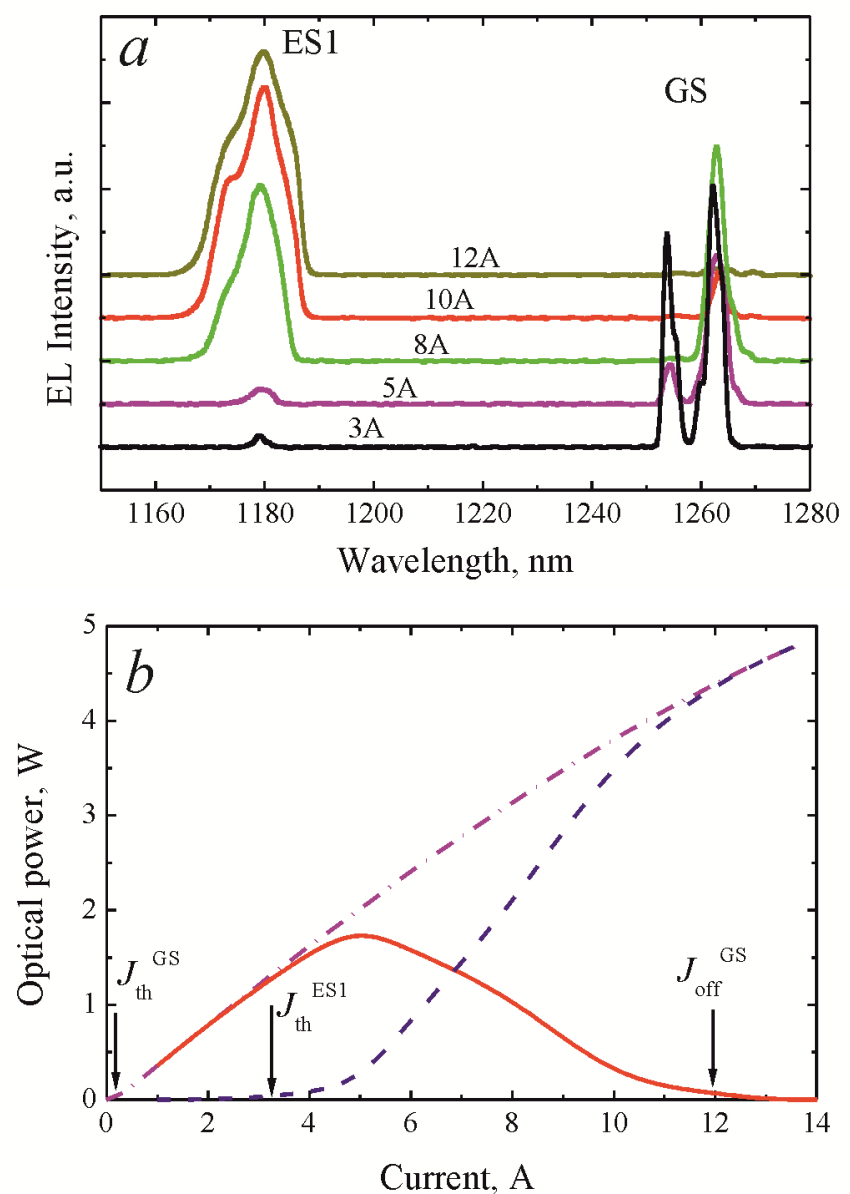

Figure 1. Lasing spectra at different currents (a); laser power (b): dashed-dotted curve - total (GS+ES1), solid curve ground-state component (GS), dashed curve - first excited-state component (ES1).

As it is seen in Figure 1,a the GS band is split into two peaks ( 1.254 and $\sim 1.262 \mathrm{~nm})$. According to M. Sugawara et al ${ }^{5}$ this splitting can be attributed to the homogenous broadening of the QD optical transition. They also suggested that the GS lasing quenching at high currents could be explained by increase of the homogenous broadening. In spite of this we found that the splitting is practically unchanged $(6.5 \pm 0.4 \mathrm{meV})$ as current increases up to $12 \mathrm{~A}$. Therefore, the quenching can not be associated with the aforementioned reason. Moreover, spectral positions of the both GS peaks also remain very stable so that the current-induced red shift is only $0.4 \mathrm{~nm}$. Such a shift corresponds to a negligible temperature increment of about $1^{\circ} \mathrm{C}$ which can not itself lead to suppression of the GS lasing because in this particular laser diode the GS lasing at low currents can be observed up to $68^{\circ} \mathrm{C}$. Thus, the GS lasing quenching at high currents can not be attributed to self-heating of the active region as well. 


\subsection{Effect of difference in electron and hole relaxation rates}

More sophisticated model that does not imply either the homogeneous broadening or self-heating effect is based on assumption of the asymmetry in charge carrier distribution in a $\mathrm{QD}^{11}$. Energy separation of ground- and excited-state energy levels of holes is much smaller than $k T$ that leads to a nearly equal probability of occupation of the hole levels. As a result, there is a competition for the "joint holes" between electrons of the ground-state and the excited-state levels. Because the ES1 electron level has a higher degeneracy as compared to the GS level, in the regime of two-state lasing the holes are effectively swept out from QDs because of their recombination with ES1 electrons. In its turn this leads to the quenching of the GS lasing as the pump current grows.
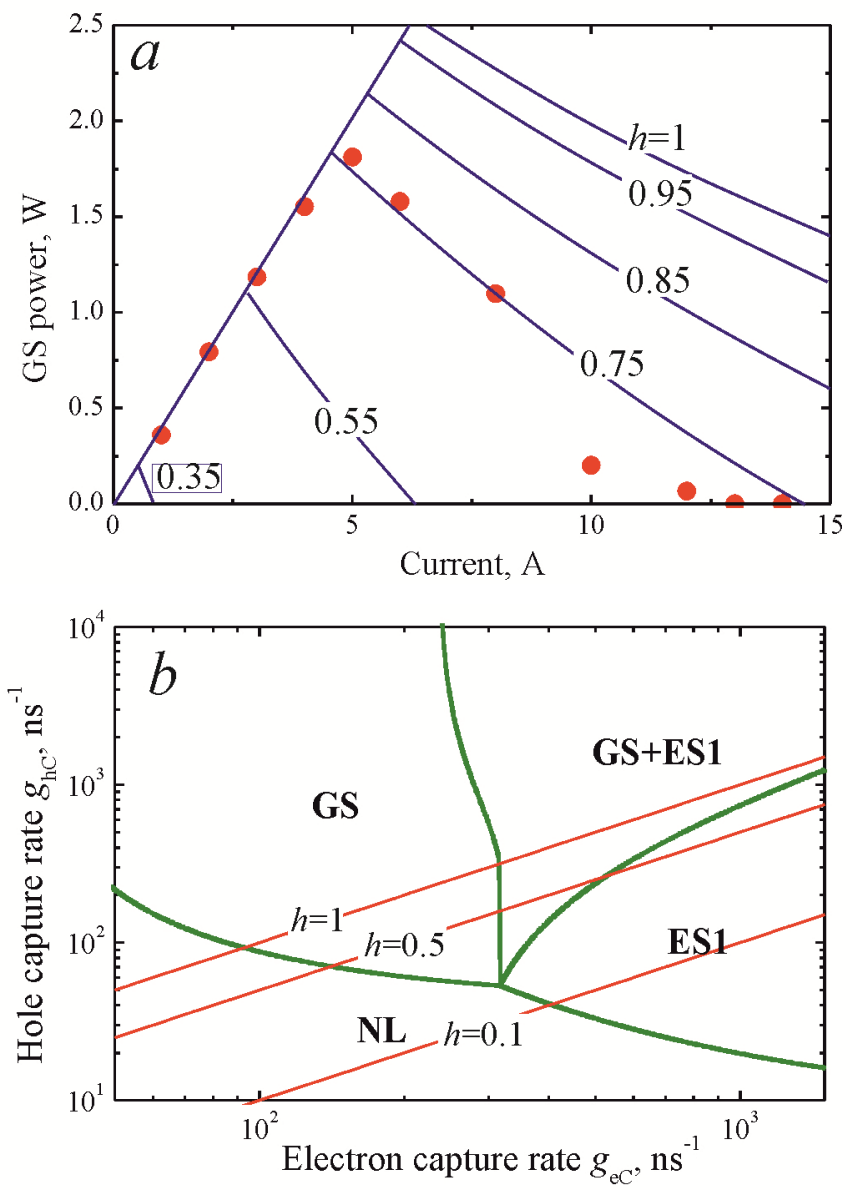

Figure 2. $L$-I curves for ground-state component (a): circles - experiment; lines - calculation for different ratio of hole-toelectron relaxation rates $(h)$. Operation diagram of QD laser: heavy lines separates regions of different lasing regimes (NL no lasing, GS - pure ground-state lasing, GS+ES1 - two-state lasing, ES1 - pure excited-state lasing); thin lines correspond to different $h$ values.

However, we found that the observed experimental data can not be quantitatively described if one takes into account only the above-mentioned asymmetry. Reasonable agreement between modeling results and experiment was achieved under assumption that electron and hole relaxation rates into QDs are different. More precisely, we assumed that the hole capture is slower than the electron one which makes the competition for holes more pronounced and leads to complete quenching of the GS lasing at lower pumps. Figure 2,a shows the calculated evolution of the GS power with the pump current. The results are shown for different ratio of the hole-to-electron relaxation rates $h$ which is assumed to be independent of the injection rate. The best agreement of the model results with the experiment is found for $h=0.75$. Lower rate of the hole relaxation is probably associated with their slower velocity in the matrix/wetting layer. Using the 
extracted value of $h$ we can also reproduce fairly well temperature dependences of the two-state lasing threshold and the current of the GS-lasing quenching.

Using the proposed model we are capable of calculating the operation diagram of QD laser as shown in Figure 2,b. The diagram depicts different regimes of the laser operation as a function of electron $\left(g_{\mathrm{eC}}\right)$ and hole $\left(g_{\mathrm{hC}}\right)$ capture rates: subthreshold regime of no lasing (NL), regime of lasing via GS optical transition (GS), two-state lasing regime (GS+ES1), regime of lasing via ES1 transition only (ES1). Depending on the ratio of hole-to-electron relaxation rates ( $h=g_{\mathrm{hC}} / g_{\mathrm{eC}}$ ) and the total optical loss various scenarios of laser behavior can be realized. In particular, in case of sufficiently fast hole capture $(h=1$ in Figure $2, \mathrm{~b})$ the two-state lasing can persist so that the GS lasing peak is not completely suppressed even at very high injection levels.

\subsection{Effect of $p$-type doping}

Modulation $p$-type doping of QDs may noticeably improve temperature stability of the threshold current ${ }^{12}$. We found that $p$-doping affects the two-state lasing behavior as well. Temperature dependences of the two-state lasing threshold current as well as the ground-state lasing threshold current are presented in Figure 3 for two 0.6-mm-long diodes of similar design (10 planes of InAs/InGaAs QDs): one with undoped active region and another with modulation doping ( $\sim 10$ acceptors per QD). The GS-lasing thresholds measured at room temperature are nearly equal in both structures $(\sim 0.35 \mathrm{~A})$. At the same time, the onset of the two-state lasing is significantly shifted to higher currents in the $p$-type doped laser $(\sim 5.5 \mathrm{~A})$ as compared to its undoped analogue ( $\sim 1.1 \mathrm{~A})$. Light-current curve (insert of Figure 3) demonstrates that the maximum optical power of the GS spectral component reaches $3.6 \mathrm{~W}$ in the laser with $p$-type doping, while it is about $2.4 \mathrm{~W}$ in the undoped counterpart. Another finding is that the temperature interval, where GS lasing can be achieved, extends to higher temperatures in the $p$-doped structure (from 55 to $100^{\circ} \mathrm{C}$ ).

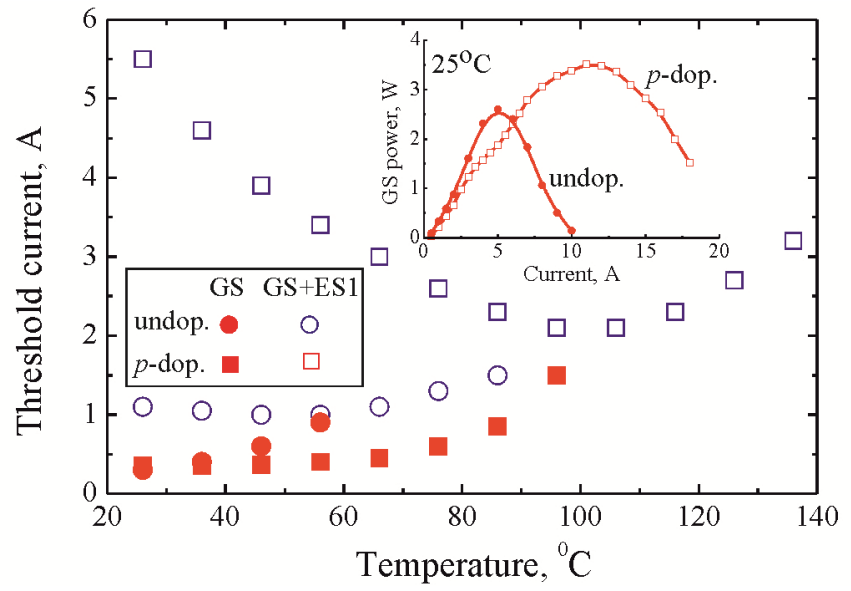

Figure 3. Threshold $v s$ temperature for ground-state lasing (solid symbols) and two-state lasing (open symbols) in lasers with undoped (circles) and $p$-type doped (squares) QDs. Insert: power of the GS-line $v s$ current.

\subsection{Comparison of lasing and spontaneous emission spectra}

Spontaneous emission spectra may provide additional information on peculiarities of the two-state lasing. We studied QD lasers having 4 cleaved facets where both lasing and spontaneous emission can be simultaneously detected as shown in Figure 4. At least five peaks of different origin are easily resolved: two narrow peaks of lasing emission via groundstate $(1264.3 \mathrm{~nm})$ and first excited-state $(1179.8 \mathrm{~nm})$ transitions and three broad peaks of spontaneous emission via ground-state $(1264.0 \mathrm{~nm})$, first excited $(1172.0 \mathrm{~nm})$ and second excited-state $(1108.4 \mathrm{~nm})$ transitions. The characteristic feature is that the GS lasing peak nearly coincides with the peak position of GS spontaneous emission. This implies that the GS lasing arises from QDs of the most probable (mean) size. At the same time ES1 lasing peak is noticeably redshifted with respect to the peak position of ES1 spontaneous emission indicating that QDs, which size is larger than the mean one, are chiefly responsible for the ES lasing. Similar behavior was observed in a wide interval of current density. 


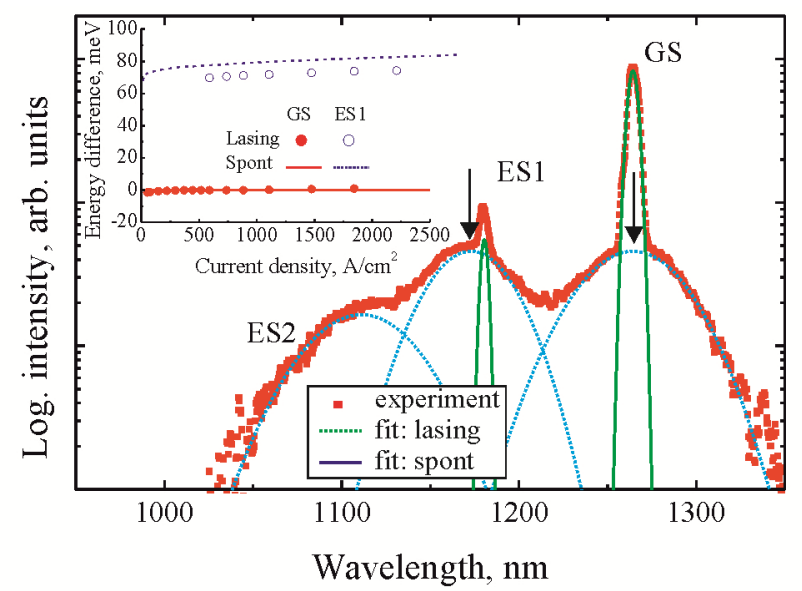

Figure 4. Emission spectrum: squares - experiment, solid curves - lasing emission, dotted curves - spontaneous emission. Insert: peak position $v s$ current density: solid circles - GS lasing, open circles - ES1 lasing, solid curve - GS spontaneous emission, dotted curve - ES1 spontaneous emission.

\section{MICRORING STRUCTURES}

\subsection{Experiment}

An epitaxial structure was grown by molecular beam epitaxy on semi-insulating GaAs(100) substrate. An active region comprises five layers of $\mathrm{InAs} / \mathrm{In}_{0.15} \mathrm{Ga}_{0.85} \mathrm{As}$ QDs separated by 30 -nm-thick GaAs spacers. The active region was inserted into a 220-nm-thick GaAs waveguiding layer confined by 20 -nm-thick $\mathrm{Al}_{0.3} \mathrm{Ga}_{0.7} \mathrm{As}$ barriers. A 400-nm-thick $\mathrm{Al}_{0.98} \mathrm{Ga}_{0.02} \mathrm{As}$ cladding layer was grown beneath the waveguiding layer. Microrings were defined by photolithography and $\mathrm{Ar}^{+}$-etching. The outer diameter was varied in different structures from $D=4$ to $9 \mu \mathrm{m}$. The inner diameter ranges from $d=0$ (microdisks) to $d \approx 0.8 D$. Finally, the cladding layer was selectively oxidized into $(\mathrm{AlGa})_{\mathrm{x}} \mathrm{O}_{\mathrm{y}}$. Typical microphotograph of the resonator structure is shown in Figure 5.

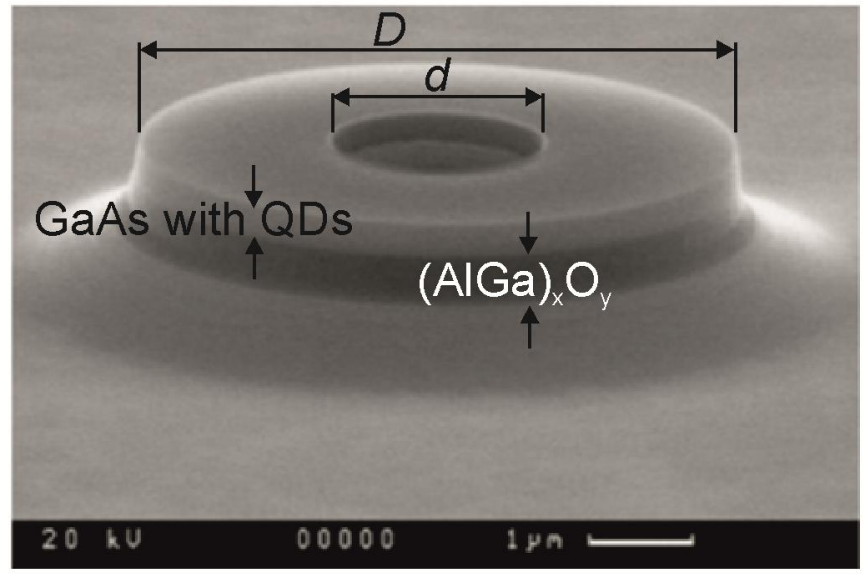

Figure 5. SEM image of QD microring laser $(D=6 \mu \mathrm{m}, d=2 \mu \mathrm{m})$.

For optical experiments a CW-operating YAG:Nd laser $(\lambda=532 \mathrm{~nm})$ was used together with a cooled Ge pin-diode. Measurements at elevated temperatures were performed with the structures mounted onto a heated holder equipped with a temperature controller. Low temperature measurements were done in a flow cryostat. 


\subsection{Low-temperature measurements}

An example of luminescence spectrum taken at $77 \mathrm{~K}$ from $6 \mu \mathrm{m}$-ring with $2 \mu \mathrm{m}$ inner diameter is shown in Figure 6 . Four series of whispering gallery modes of different radial order are clearly observed. All modes presented in the optical spectrum were identified by means of 2D-axisymmetric analysis. The dominant modes are of $n=2$ and 3 order. Significant overlap of many modes exists (e.g. around $1190.8 \mathrm{~nm}$ where 3 modes are close together).

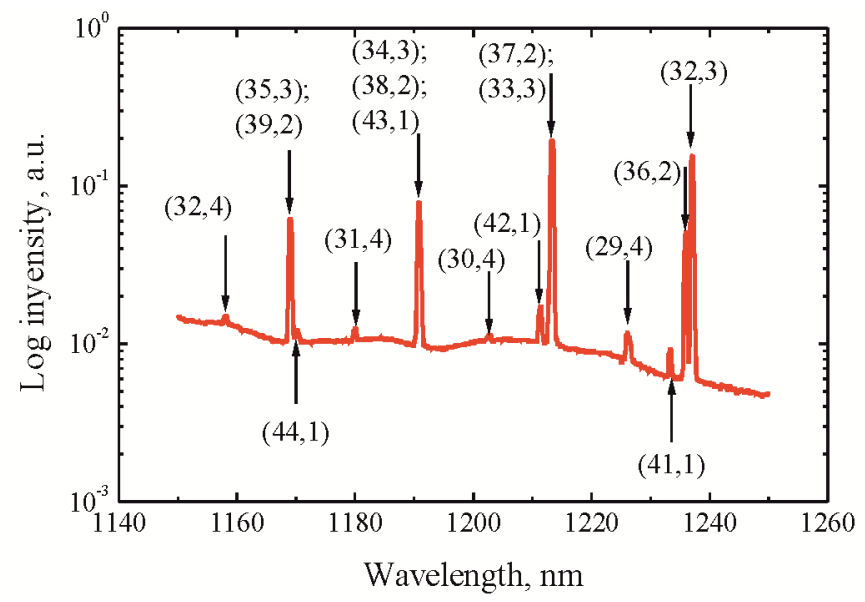

Figure 6. Low-temperature luminescence spectrum of the microring. Estimated mode orders $\mathrm{TE}_{m, n}$ are indicated near the peaks.

\subsection{Near-field scanning optical microscopy.}

Spatial distribution of light intensity inside the microresonators was studied by means of near-field scanning optical microscopy (NSOM). Several typical NSOM images are presented in Figure 7. Characteristic WGM patterns are clearly seen. Depending on spectral position of the luminescence peaks, NSOM images reveal modes of different radial and azimuthal order.

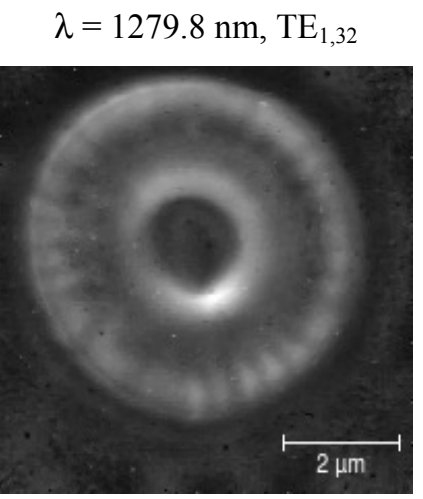

$$
\lambda=1291.3 \mathrm{~nm}, \mathrm{TE}_{2,29}
$$

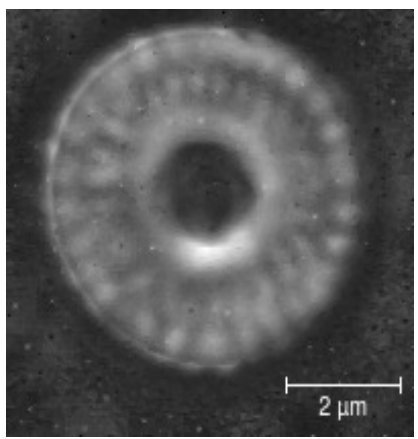

Figure 7. NSOM images demonstrating WGM modes of different orders in the microring resonator.

\subsection{Room-temperature measurements.}

A representative room-temperature $\mu$-PL spectrum taken under low excitation is shown in the left insert of Figure 8. Full width at half maximum for resonant peaks varies from 0.143 to $0.234 \mathrm{~nm}$ giving the quality factor of about 9000 .

The threshold power for the microring/microdisk structures was estimated from a light-light curve of the dominant mode. An example is presented in Figure 8 where a characteristic knee is clearly seen. In this particular case $(D=7 \mu \mathrm{m}$, 
$d=3.4 \mu \mathrm{m}$ ) the threshold power is $0.37 \mathrm{~mW}$. No correction was made to take into account partial light reflection from the surface or waste of the excitation power in the inner area of microring structures. Overall the threshold power at room temperature in different structures ranges from few tenths of $\mathrm{mW}$ to few $\mathrm{mW}$. From one to three modes were usually observed in room-temperature lasing spectra (see right insert of Figure 8).

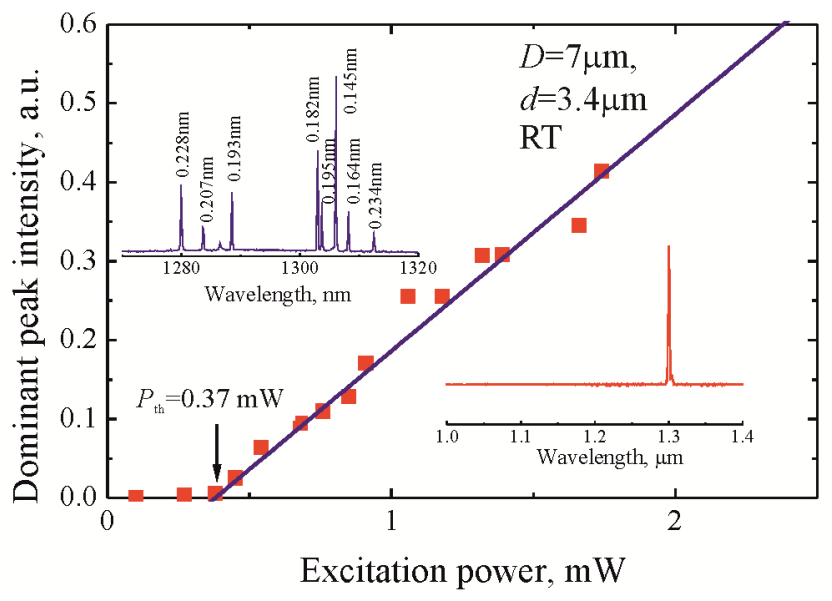

Figure 8. Intensity of the dominant mode against excitation power (symbols). Curve is a guide to the eye. Insert: luminescence spectrum below threshold (left) and above threshold (right).

Room-temperature threshold characteristics of the microstructures with different inner diameters were compared. In most cases the threshold power (absolute value) decreases by approximately $30-40 \%$ as the inner diameter increases from 0 (disk) to 0.3-0.6 D, see Figure 9. Further ring thinning results in rapid growth of the threshold. As for the effect of the outer diameter, the lowest threshold of 0.37-0.4 mW was found in microrings having an outer diameter of 6-7 $\mu \mathrm{m}$. Both larger and smaller microrings demonstrate higher threshold power as shown in the insert of Figure 9.

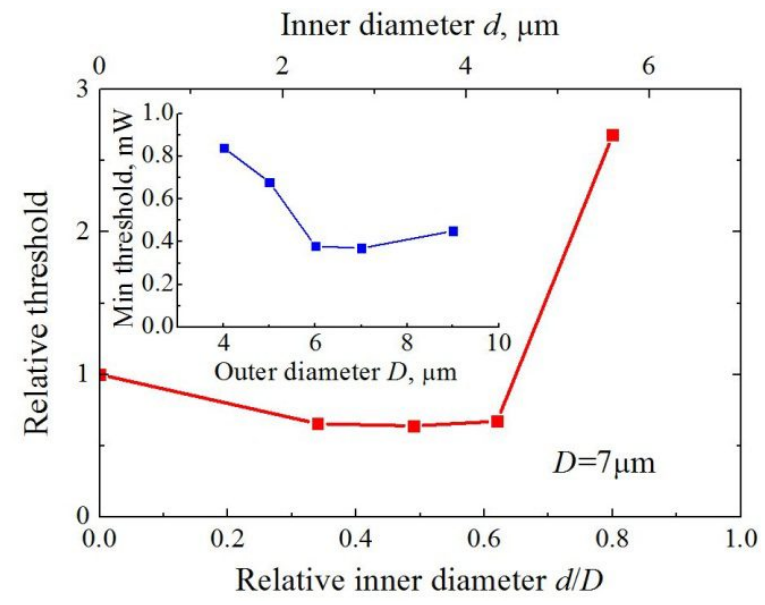

Figure 9. Room-temperature threshold (normalized to the threshold of the microdisk structure) as a function of inner diameter. Insert: the lowest threshold against the outer diameter.

\subsection{High-temperature measurements}

Threshold power increases super-exponentially with temperature. Around room temperature the characteristic temperature was estimated to be $\sim 60-75 \mathrm{~K}$. In most cases, lasing can be observed up to $80-90^{\circ} \mathrm{C}$ whereas the highest temperature of lasing was found to be as high as $107^{\circ} \mathrm{C}$, Figure 10 . To the best of our knowledge this is the highest 
temperature ever reported for $1.3 \mu \mathrm{m}$ QD MRLs. Below room temperature the threshold is nearly unchanged or even slightly increases. Temperature variation of the lasing wavelength is summarized in Figure 10. Spectral position of the ground-state optical transition of quantum-dot luminescence is also shown for comparison. It is seen that the lasing wavelength is quite stable $(\sim 0.05 \mathrm{~nm} / \mathrm{K})$ within relatively wide temperature intervals (e.g. from 20 to $40^{\circ} \mathrm{C}$ and then from 50 to $90^{\circ} \mathrm{C}$ ) where a certain WGM mode remains the dominant one. Abrupt changes of the lasing wavelength (e.g. around $40-50{ }^{\circ} \mathrm{C}$ ) are due to hopping of the dominant mode.

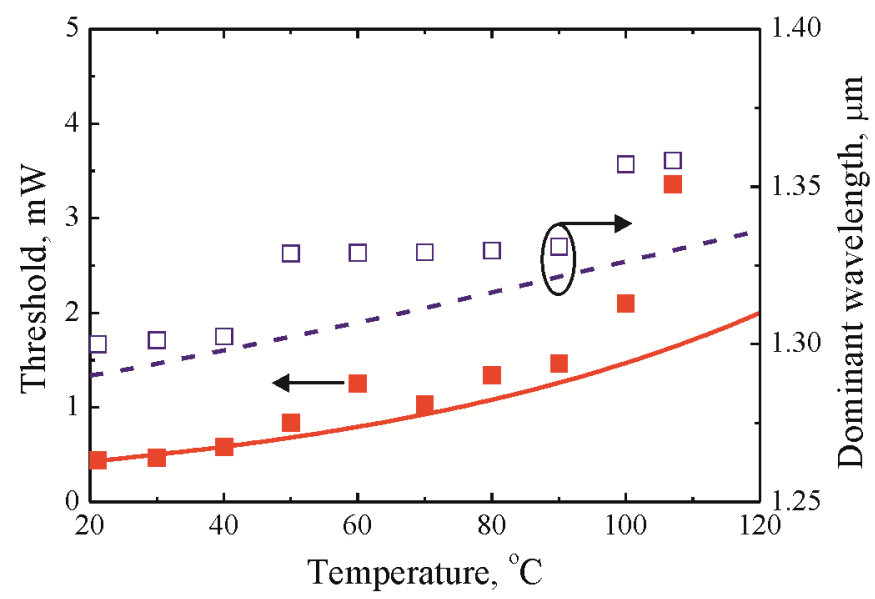

Figure 10. Temperature dependences of the threshold power (solid symbols) and wavelengths of the dominant mode (open symbols). QD ground-state optical transition against temperature (dashed curve) is also shown. Solid curve is exponential fit with $T_{0}=65 \mathrm{~K}$.

\section{CONCLUSIONS}

Quantum dot lasing structures of two sorts both emitting around $1.3 \mu \mathrm{m}$ were studied: broad-area diode lasers and optically pumped microresonators.

Broad-area lasers were used for detailed investigation of the two-state lasing phenomenon and, in particular, quenching of the ground-state lasing emission that observed at high currents. It was demonstrated that the most probable reason for the GS lasing quenching is asymmetry of electrons and holes carrier distributions. Additionally, difference in capture rates of electrons and holes has to be taken into consideration. We also found that the GS-component reaches its maximum beyond the threshold of the two-state lasing and that different groups of QDs are responsible for GS- and ES1lasing in the two-state lasing regime. Finally, we demonstrated that $p$-type modulation doping of QDs leads to noticeable suppression of the ES1-lasing thereby resulting in enhancement of peak power of the GS spectral component.

Microrings and microdisks of few micrometers in diameter were made by ion etching and selective oxidation with Qfactor of about 9000 . Whispering gallery modes of second and third radial orders dominate the luminescence spectrum. Nearly single-mode lasing was observed at elevated temperatures. The lowest threshold (around $0.4 \mathrm{~mW}$ at RT) was found in microdisks of intermediate diameter $(6-7 \mu \mathrm{m})$ with approximately $50 \%$ inner aperture. The highest temperature was found to be $107^{\circ} \mathrm{C}$ and the threshold was in $\mathrm{mW}$-range.

\section{ACKNOWLEDGEMENTS}

The work is supported in different parts by Russian Ministry of Science and Education, Russian Foundation for Basic Research, Programs of Fundamental Studies of the Russian Academy of Sciences. NVK is thankful for support to SaintPetersburg`s Committee on Science and Higher School. 


\section{REFERENCES}

[1] Zhukov, A. E., Kovsh, A. R., Livshits, D. A., Ustinov, V. M. and Alferov, Zh. I., "Output power and its limitation in ridge-waveguide $1.3 \mu \mathrm{m}$ wavelength quantum-dot lasers," Semicond. Sci. Technol. 18(8), 774-781 (2003).

[2] Markus, A., Chen, J. X., Gauthier-Lafaye, O., Provost, J.-G., Paranthoën, C. and Fiore, A., "Impact of intraband relaxation on the performance of a quantum-dot laser," IEEE J. Select. Topics Quantum Electron. 9(5), 13081314 (2003).

[3] Markus, A. and Fiore, A., "Modeling carrier dynamics in quantum-dot lasers," phys. stat. sol. (a) 201(2), 338344 (2004).

[4] Ji, H.-M., Yang, T., Cao, Y.-L., Xu, P.-F., Gu, Y.-X. and Wang, Zh.-G., "Self-heating effect on the two-state lasing behaviors in 1.3- $\mu \mathrm{m}$ InAs-GaAs quantum-dot lasers," Jpn. J. Appl. Phys. 49(7), 072103 (2010).

[5] Sugawara, M., Hatori, N., Ebe, H., Ishida, M., Arakawa, Y., Akiyama, T., Otsubo, K. and Nakata, Y., "Modeling room-temperature lasing spectra of $1.3-\mu \mathrm{m}$ self-assembled InAs/GaAs quantum-dot lasers: Homogeneous broadening of optical gain under current injection,” J. Appl. Phys. 97(4), 043523 (2005).

[6] Liang, D., Fiorentino, M., Srinivasan, S., Bowers, J. E. and Beausoleil, R. G., "Low threshold electricallypumped hybrid silicon microring laser," IEEE J. Selected Topics Quantum Electron., 17(6), 1528 - 1533 (2011).

[7] Ouyang, D., Ledentsov, N. N., Bimberg, D., Kovsh, A. R., Zhukov, A. E., Mikhrin S. S. and Ustinov, V. M., "High performance narrow stripe quantum-dot lasers with etched waveguide," Semicond. Sci. Technol. 18(12) L53-L54 (2003).

[8] Cao, H., Xu, J. Y., Xiang, W. H., Ma, Y., Chang, S.-H., Ho, S. T. and Solomon, G. S., "Optically pumped InAs quantum dot microdisk lasers," Appl. Phys. Lett. 76(24), 3519-3521 (2000).

[9] Ide, T., Baba, T., Tatebayashi, J., Iwamoto, S., Nakaoka, T. and Arakawa, Y., "Room temperature continuous wave lasing in InAs quantum-dot microdisks with air cladding," Opt. Express 13(5), 1615-1620 (2005).

[10] Munsch, M., Claudon, J., Malik, N. S., Gilbert, K., Grosse, P., Gerard, J.-M., Albert, F., Langer, F., Schlereth, T., Pieczarka, M. M., Hofling, S., Kamp, M., Forchel, A. and Reitzenstein, S., "Room temperature, continuous wave lasing in microcylinder and microring quantum dot laser diodes," Appl. Phys. Lett. 100(3), 031111 (2012).

[11] Viktorov, E. A., Mandel, P., Tanguy, Y., Houlihan, J. and Huyet, G., "Electron-hole asymmetry and two-state lasing in quantum dot lasers," Appl. Phys. Lett. 87(5), 053113 (2005).

[12] Fathpour, S., Mi, Z., Bhattacharya, P., Kovsh, A. R., Mikhrin, S. S., Krestnikov, I. L., Kozhukhov, A. V., and Ledentsov, N. N., "The role of Auger recombination in the temperature-dependent output characteristics $\left(\mathrm{T}_{0}=\infty\right)$ of p-doped $1.3 \mu \mathrm{m}$ quantum dot lasers," Appl. Phys. Lett. 85(2), 5164-5166 (2004). 
Proc. of SPIE Vol. $8553855301-28$

Downloaded From: https://www.spiedigitallibrary.org/conference-proceedings-of-spie on 26 Apr 2023 Terms of Use: https://www.spiedigitallibrary.org/terms-of-use 